\title{
ST Segment Elevation by ECG Finding
}

National Cancer Institute

\section{Source}

National Cancer Institute. ST Segment Elevation by ECG Finding. NCI Thesaurus. Code C50540.

An electrocardiographic finding of ST segment elevation above the baseline. 